\title{
An Electrostatic Nursery Shelter for Raising Pest and Pathogen Free Tomato Seedlings in an Open-Window Greenhouse Environment
}

\author{
Yoshihiro Takikawa ${ }^{1}$, Yoshinori Matsuda ${ }^{2}$, Teruo Nonomura ${ }^{2}$, Koji Kakutani $^{3}$, Kiyotsugu Okada ${ }^{4}$, Shinya \\ Morikawa ${ }^{4}$, Manabu Shibao ${ }^{4}$, Shin-ichi Kusakari ${ }^{4} \&$ Hideyoshi Toyoda ${ }^{2}$ \\ ${ }^{1}$ Plant Center, Institute of Advanced Technology, Kinki University, Wakayama, Japan \\ ${ }^{2}$ Laboratory of Phytoprotection Science and Technology, Faculty of Agriculture, Kinki University, Nara, Japan \\ ${ }^{3}$ Pharmaceutical Research and Technology Institute, Kinki University, Osaka, Japan \\ ${ }^{4}$ Research Institute of Environment, Agriculture and Fisheries, Osaka Prefecture, Japan \\ Correspondence: Yoshinori Matsuda, Laboratory of Phytoprotection Science and Technology, Faculty of \\ Agriculture, Kinki University, Nara 631-8505, Japan. Tel: 81-742-435223. Fax: 81-742-435223. E-mail: \\ ymatsuda@nara.kindai.ac.jp
}

Received: December 29, 2015 Accepted: February 23, 2016 Online Published: March 15, 2016

doi:10.5539/jas.v8n4p13 URL: http://dx.doi.org/10.5539/jas.v8n4p13

\begin{abstract}
The electrostatic nursery shelter reported in this work was a transparent film-covered rectangular box with three electric field screens on each of the long sides of the box. This arrangement prevents flying pests and airborne fungal pathogens from entering the nursery space. Insulated conducting wires (ICWs) were used as electrodes to create electric fields. The ICWs were arrayed in parallel, and linked to direct-current voltage sources. The ICW layers were negatively or positively charged with equal voltages to form dipoles; i.e., ICW $(-)$ and $\operatorname{ICW}(+)$. The electric field screen consisted of three layers of the ICWs; i.e., an ICW(-) layer on either side of an ICW $(+)$ layer. Four species of major tomato pests were used in a blowing assay: whiteflies (Bemisia tabaci), western flower thrips (Frankliniella occidentalis), green peach aphids (Myzus persicae) and tomato leaf miner flies (Liriomyza sativae). The ICWs were located to capture test pests that were mechanically blown into the electric-field screen. The electrostatic force to capture the insects was directly proportional to the applied voltage, and at voltages of $1.2 \mathrm{kV}$ or greater, the screen exerted sufficient force to capture all of the test pests. An assay in a pest-infested greenhouse revealed that the ICWs captured all the pests that approached the screen, and the plants within the shelter remained pest-free. In addition, we show that the electric-field-screened shelter remained spore-free in the presence of continuous exposure to the conidia of tomato powdery mildew (Oidium neolycopersici).
\end{abstract}

Keywords: electric field screen, green house pests, tomato powdery mildew

\section{Introduction}

The single-truss cropping system is a method of fruit cropping commonly used in hydroponic cultivation of tomatoes (Giacomelli et al., 1994). In our system of single-truss cropping, two cultivation steps are involved: seedlings are raised in a nursery, and then propagated for cropping. The most serious problem faced with such greenhouse-based tomato production is damage to young tomato seedlings at the nursery stage resulting from pests and pathogens. Tomato plants at this stage frequently suffer from infections due to air-borne conidia of tomato powdery mildew (Oidium neolycopersici) (Kashimoto et al., 2003a; Matsuda et al., 2001) and/or attack from viruliferous whiteflies (Bemisia tabaci) (Tanaka et al., 2008). This is because the plants are grown in open-window greenhouses. Seedlings in the nursery are highly susceptible to disease, and many seedlings wither because of infection due to powdery mildew conidia on the cotyledonal or primary leaves, or vigorous multiplication of whitefly-transmitted viruses in the growing region and the upper leaves of the young seedlings. The plants are less affected by the pests and pathogens in the propagation stage, whereby the plants have the growing point removed after the production of 2-3 leaves above the first fruit cluster, and all lateral shoots are removed as the plant grows. One of the main advantages of single-truss crop production is the short time from planting to harvest, leading to reduced usage of agrochemicals such as fungicides and insecticides during this plant-propagation period. We have succeeded in harvesting tomato fruits at ordinary levels using two on-site methods: instantaneous eradication of immature fungal colonies on leaves using a portable corona discharger 
(Nonomura et al., 2008), and direct elimination of leaf-nesting pests using a portable electrostatic insect sweeper (Takikawa et al., 2015), both of which were applied during routine care of greenhouse tomatoes.

Our routine survey of the occurrence of the powdery mildew in nursery-stage seedlings at different seasons of the year revealed that pathogens first appear on a few leaves, after which progeny conidia rapidly develop and spread disease to neighboring plants. The disease spreads rapidly throughout the seedlings in well-ventilated greenhouses, especially when chemical control is insufficient. At present, chemical methods are effective in controlling the powdery mildew pathogen and are indeed essential. Nevertheless, new fungicide-tolerant lines of pathogens may arise as a result of frequent applications of fungicide. A preliminary survey revealed that azoxystrobin-insensitive isolates of tomato powdery mildew are already present on naturally infected tomato leaves, although some fungicides (including benomyl, fenarimol, pyrazophos, thiabendazol and toriforine) remain effective toward these pathogens (Mori et al., 2004). It is desirable to reduce the usage of fungicides in response to environmental concerns, and we have focused on the development of physical methods of disease control.

The transmission of plant viruses, primarily the Geminiviruses, is another serious problem that affects nursery-stage seedlings of tomatoes (Cohen \& Berlinger, 1986; Oliveira et al., 2001). Whitefly is a significant virus-transmitting pest in tomato cultivation in Japan (Ueda et al., 2006). This pest is difficult to control using insecticides, because they feed and deposit eggs mainly on the abaxial surface of the leaves (Sharaf, 1986), and because they have developed resistance to many classes of insecticide that are commonly applied to control them (Prabhaker et al., 1985; Palumbo et al., 2001; Horowitz et al., 2004; Nauen \& Denholm, 2005). Physical methods provide a potential alternative means of managing these pests, since they would be compatible with other components of integrated pest management, have little impact on the environment, and reduce pesticide use, thus slowing the development of insecticide resistance (Weintraub \& Berlinger, 2004).

Here we examine the efficacy of an electrostatic nursery shelter to provide a spore-free and pest-free environment for nursery-stage tomato seedlings. We have previously described a three-layer double-charged dipolar electric field (3L-DD) screen, which was devised for trapping air-borne spores of Penicillium degitatum (Takikawa et al., 2014). Here we examine its ability to trap air-borne conidia of the tomato powdery mildew, as well as four major greenhouse pests; i.e., whiteflies, western flower thrips (Frankliniella occidentalis), green peach aphids (Myzus persicae) and tomato leaf-minor flies (Liriomyza sativae).

\section{Materials and Methods}

\subsection{Pathogen and Plants}

We investigated conidia from $O$. neolycopersici KTP-01 (Kashimoto et al., 2003b), as well as the tomato cultivars Moneymaker and Micro-Tom (Solanum lycopersicum), which are highly susceptible to KTP-01 (Matsuda et al., 2005a). Germinated seeds of Moneymaker were sown in vermiculite in a tray, and 10-day-old seedlings were transplanted in 15-cm-diameter pots. The plants were grown in a closed-window greenhouse for 20 days, and then transferred to an inoculation greenhouse. The temperature in both greenhouses was controlled at $25 \pm 3{ }^{\circ} \mathrm{C}$. The conidia were maintained on leaves of 1-month-old seedlings of Micro-Tom according to the method described by Kashimoto et al. (2003b). Newly produced conidia of 8-day-old powdery mildew colonies on leaves were used in subsequent experiments.

\subsection{Pest Insects}

Adults of whitefly (Bemisia tabaci Gennadius, type Q, virus-free) were collected from greenhouse-grown tomatoes and reared on tomato plants in a temperature-controlled greenhouse $\left(26 \pm 2{ }^{\circ} \mathrm{C}\right.$ temperature, $35-55 \%$ relative humidity) (Matsuda et al., 2013). Male and female adults that multiplied on the tomato plants were collected using an insect aspirator (Wildlife Supply, Binghamton, NY). In addition to $B$. tabaci, the other three species used were green peach aphids (Myzus persicae Sulzer), Western flower thrips (Frankliniella occidentalis Pergande) and tomato leaf miner flies (Liriomyza sativae Blanchard). These insects were purchased from Sumika Technoservice (Hyogo, Japan). Adult Western flower thrips and wingless adult female green peach aphids were reared on water-swollen seeds and 1-week-old broad bean seedlings (Vicia faba L. 'GB-Blend'), using the methods described by Murai (1991) and Murai and Loomans (2001), respectively. The winged adult female green peach aphids and adult male and female Western flower thrips of the resultant progenies were collected using an insect aspirator, and used in the experiments. Adult leaf miner flies were released on potted 1-month-old tomato seedlings in a greenhouse with the same conditions as described above. Pupae that fell onto the soil in the pots were collected in a Petri dish, and hatched adult flies were collected using an insect aspirator. The average body size of the insects (i.e., length from head to wing tip, $\mathrm{n}=20$ adults of each species) was $0.78 \pm 0.09 \mathrm{~mm}$ for the whiteflies, $3.75 \pm 0.27 \mathrm{~mm}$ for the green peach aphids, $1.46 \pm 0.13 \mathrm{~mm}$ for the Western flower thrips, and 
$3.93 \pm 0.37 \mathrm{~mm}$ for the leaf miner flies.

\subsection{Electrostatic Nursery Shelter}

$\mathbf{a}$

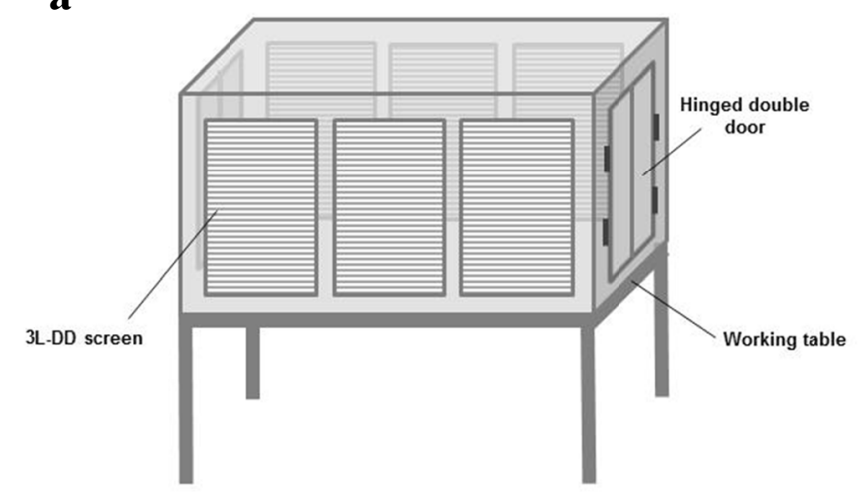

b

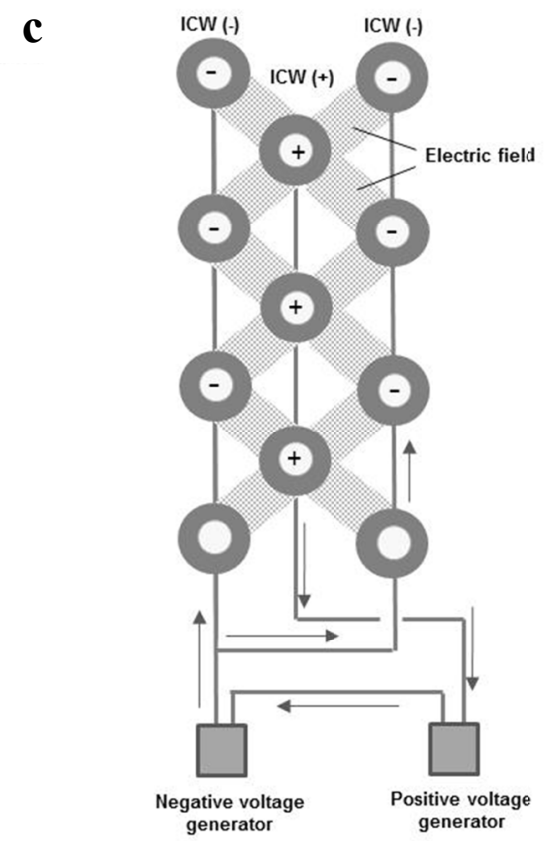

Figure 1. (a) Schematic diagram of the electrostatic nursery shelter. (b) The components of the electric field screen. (c) A cross-sectional view of insulated conducting wires (ICWs) in the electric field screen. The layers of ICWs are arrayed in parallel and linked to DC voltage generators. The electric field is formed between ICW(-) and $\operatorname{ICW}(+)$. The arrows show the direction of flow of current between $\operatorname{ICW}(-)$ and $\operatorname{ICW}(+)$ to form the electric field

The electrostatic nursery shelter was fabricated in the form of an electric-field-screened box with dimensions of $90 \mathrm{~cm} \times 90 \mathrm{~cm} \times 180 \mathrm{~cm}$, which was placed on a 60-cm-high steel worktable with a surface area of $90 \mathrm{~cm} \times 180$ $\mathrm{cm}$, as shown in Figure 1a. Hinged double-doors were attached to the two shorter lateral faces of the box, and the top surface was covered with a transparent polyvinyl film. Three $3 \mathrm{~L}-\mathrm{DD}$ screens $(60 \mathrm{~cm} \times 85 \mathrm{~cm})$ were installed on each of the longer lateral faces of the box. The screen had two components: three layers of insulated conducting iron wires (ICWs) in parallel arrays, and two electrostatic direct current (DC) voltage sources (voltage generator DMS-P and DMS-N; Max Electronics, Tokyo, Japan), which supplied negative and positive voltages to the ICWs, respectively, as shown in Figure 1b. Iron conducting wires that were $2 \mathrm{~mm}$ in diameter and 55 -cm-long were insulated by passing them through a transparent insulating vinyl sleeve that was 1-mm-thick and had a bulk resistivity of $1 \times 10^{9} \Omega \cdot \mathrm{m}$. The screen was constructed with a slight modification to the previous 
method (Takikawa et al., 2014), so that the ICWs of each layer were placed in parallel with a separation of $5 \mathrm{~mm}$, and were connected to either a negative or positive voltage source. The negatively charged ICWs were labelled $\mathrm{ICW}(-)$, and the positively charged ICWs are labelled ICW(+), as shown in Figure 1c. The screen consisted of one ICW $(+)$ layer with two ICW $(-)$ layers, one located on either side of the ICW $(+)$ layer. These layers located in parallel were separated by $2 \mathrm{~mm}$, and the ICWs in the different layers were offset from each other. The voltage sources were linked to create an electric circuit producing an electric field between the ICW $(-)$ and ICW $(+)$ insulated wires. Both voltage sources were operated using $12-\mathrm{V}$ storage batteries, with the power supplied by a $15-\mathrm{W}$ solar panel to supply equal negative and positive voltages $(0.4-1.4 \mathrm{kV})$ to the ICWs. In this system, free electrons from $\mathrm{ICW}(+)$ were pushed out to the $\mathrm{ICW}(-)$, and the opposite surface charges on the ICWs acted as dipoles that formed an electric field between them.

\subsection{Assay for Capturing Pests Using the 3L-DD Screen}

The $3 \mathrm{~L}-\mathrm{DD}$ screen was operated at voltages in the range $0.4-1.4 \mathrm{kV}$ to investigate the required voltage to capture all of the test insects. Adult insects were blown into the space between the ICWs by sending compressed air (1.5 $\mathrm{kg} \mathrm{cm}^{-2}$ ) through the tip of an insect aspirator, as shown in Figure 2a. The distance between the tip of the aspirator and the surface of the ICWs was varied to provide wind speeds in the range $1-3 \mathrm{~m} \mathrm{~s}^{-1}$ (Note that all side and roof windows of the greenhouse were automatically closed when the outside air speed reached $3 \mathrm{~m} \mathrm{~s}^{-1}$, and opened again when the wind speed decreased to $1.5 \mathrm{~m} \mathrm{~s}^{-1}$ ). The wind speed was measured at the surface of the ICW using a high-sensitivity anemometer (Climomaster 6533; Kanomax, Tokyo, Japan). To confirm the successful capture of the insects with the ICW, we directed the blower (with a maximum wind speed of $7 \mathrm{~m} \mathrm{~s}^{-1}$ at the ICW) at the captured insects for $10 \mathrm{~min}$. Twenty adults were used for each voltage tested and for each insect species. The experiments were repeated three times, and data are presented as the mean and standard deviation (SD). The significance of the data was analyzed statistically, as described in the caption to Table 1.

\subsection{Biotype Identification of Trapped Whiteflies and Virus Detection in Whiteflies}

To identify the biotypes of the whiteflies that infested tomato plants in our greenhouse, we collected single whiteflies from the plants and mixed their homogenates with a reaction mixture from a commercial biotype detection kit (i.e., Nippon Gene, Tokyo, Japan) with a loop-mediated isothermal amplification (LAMP) of specific genome sequences of the whiteflies (Hsieh et al., 2012). 
$\mathbf{a}$

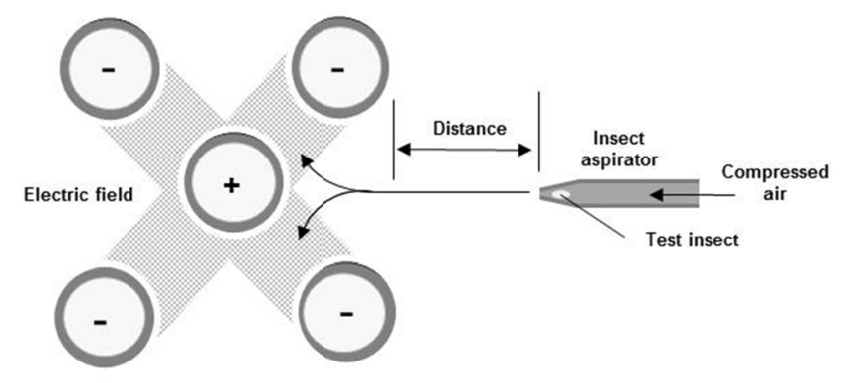

b

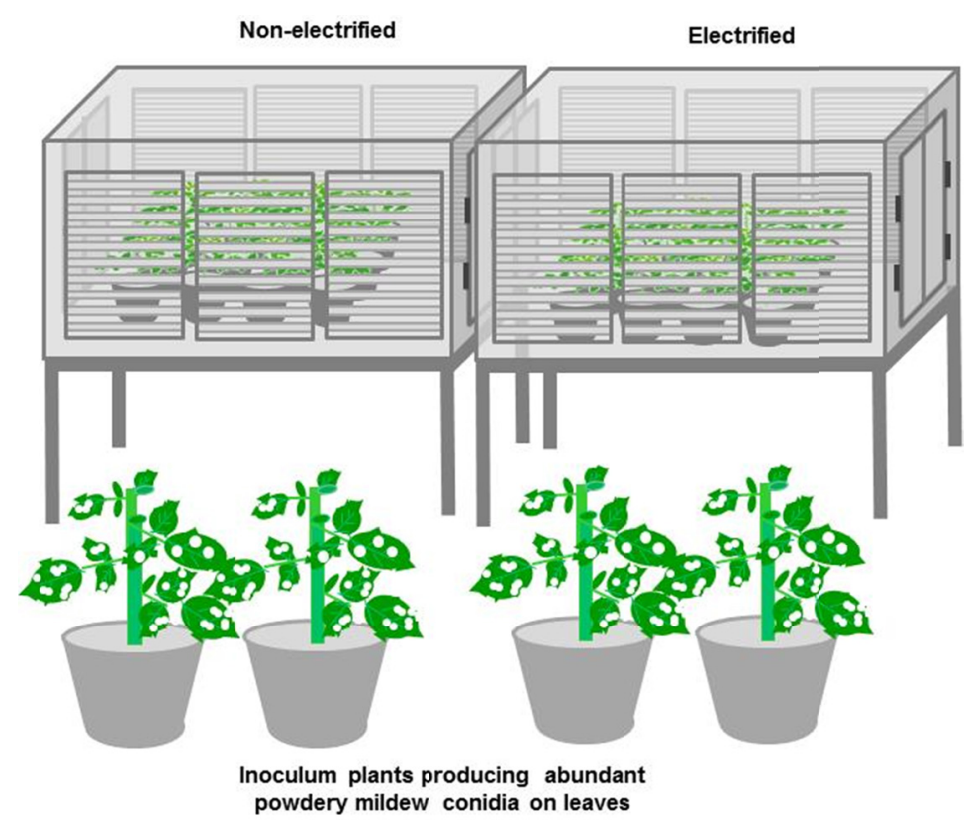

Figure 2. (a) A schematic diagram showing the mechanism of pest capture within the screen. Insects were blown toward the 3L-DD screen from an insect aspirator using compressed air. The arrows show the direction of the path taken by the insects due to the electrostatic forces. (b) Mechanical dissemination of conidia produced on the leaves of the inoculum plants toward the electrified and non-electrified nursery shelters containing tomato seedlings

To detect tomato yellow leaf curl virus (TYLCV) in the trapped whiteflies, we pierced the whiteflies using sterilized toothpicks and then dipped the toothpicks in a solution from a commercial TYLCV-detection kit (Nippon Gene) for LAMP of viral DNA (Fukuta et al., 2003). Both experiments were carried out according to the manufacturers' protocols. A total of 10 whiteflies per plant were collected at random from 10 plants every three weeks to determine the whitefly biotype and to identify viruses they may have carried.

\subsection{Greenhouse Pest Exclusion Assay}

A total of 400 insect-free, healthy, 40-day-old tomato plants (30-day-old Moneymaker seedlings) were transplanted into hydroponic culture troughs of a propagation greenhouse. Yellow sticky plates $(25.7 \times 10 \mathrm{~cm})$ (Y-plates; Arysta Life Science, Tokyo, Japan) were hung from a crossbeam at 1-m intervals to monitor the invasion of pest insects (whiteflies and tomato leaf miner flies). Insects trapped on the Y-plates were counted every three weeks for three months. A large population of the pests was maintained by adding new tomato plants to the hydroponic troughs throughout the experimental periods of six months, including the period of the insect exclusion assay (see below). 
Electrified and non-electrified electrostatic nursery shelters were located in the pest-infested greenhouse for a period of three weeks to examine the insect exclusion efficacy. Twenty healthy Moneymaker seedlings ( 1 month old) were placed in each shelter. Four experiments were carried out from July (when heavy whitefly infestation was confirmed in other tomato greenhouses) to September 2014. At the end of each experiment, we counted the number of the whiteflies and tomato leaf miner flies that had colonized the leaves of the plants and the number of them trapped by the ICWs of the 3L-DD screens.

\subsection{Spore Blowing Assay in a Greenhouse}

The electrostatic nursery shelter was tested in a greenhouse for its spore-trapping ability using a mechanical blower. Two shelters were used for this assay: electrified with a voltage of $1.2 \mathrm{kV}$ and non-electrified. Twenty uninfected Moneymaker tomato plants were placed inside the shelter, and two KTP-01-inoculated tomato plants (2-month-old seedlings), producing abundant conidia on their leaves, were placed $2 \mathrm{~m}$ in front of each shelter for inoculation, as shown in Figure $2 b$. The conidia were disseminated from the leaves via an electric fan, which supplied air toward the shelters over the inoculum plants at velocity of $3.0 \mathrm{~m} \mathrm{~s}^{-1}$ for 1 hour each day for a period of 3 weeks. The wind velocity was measured at the site of the ICWs using an anemometer. The appearance of fungal colonies on the leaves of the plants located in the shelters was examined at the end of experiment. The experiments were repeated three times. The surfaces of the tomato leaves and the ICWs were scanned using a high-fidelity digital microscope to observe the conidia using the method described previously by Matsuda et al. (2005b). The inoculation efficiency was expressed as the number of plants with at least one powdery mildew colony on its leaves.

\section{Results}

In the first experiment, we examined the ability of the 3L-DD screen to capture released adult insects with various body sizes. Table 1 lists the percentage of insects captured by the screen at various voltages in the range $0.4-1.4 \mathrm{kV}$, and for various wind speeds in the range $1.0-3.0 \mathrm{~m} \mathrm{~s}^{-1}$.

Table 1. The percentage of test insects captured by the ICWs of a doubly charged electric field screen (3L-DD screen)

\begin{tabular}{|c|c|c|c|c|c|c|c|c|c|c|c|}
\hline \multirow{2}{*}{ Wind speed $\left(\mathrm{m} \mathrm{s}^{-1}\right)$} & \multirow{2}{*}{ Test insects } & \multicolumn{10}{|c|}{ Negative and positive voltages $(\mathrm{kV})$ applied to ICWs } \\
\hline & & 0 & 0.4 & 0.6 & & 0.8 & & 1 & & 1.2 & 1.4 \\
\hline \multirow[t]{4}{*}{1} & Whitefly & 0 & 0 & $41.7 \pm 6.3$ & a & 100 & a & 100 & a & 100 & 100 \\
\hline & Western flower thrips & 0 & 0 & $9.2 \pm 6.7$ & $\mathrm{~b}$ & 100 & a & 100 & a & 100 & 100 \\
\hline & Green peach aphid & 0 & 0 & 0 & $\mathrm{c}$ & 100 & a & 100 & a & 100 & 100 \\
\hline & Tomato leaf miner fly & 0 & 0 & 0 & $\mathrm{c}$ & $48.7 \pm 4.8$ & $\mathrm{~b}$ & 100 & a & 100 & 100 \\
\hline \multirow[t]{4}{*}{2} & Whitefly & 0 & 0 & $12.1 \pm 4.9$ & $\mathrm{~b}$ & 100 & a & 100 & a & 100 & 100 \\
\hline & Western flower thrips & 0 & 0 & 0 & $\mathrm{c}$ & $51.7 \pm 7.9$ & $\mathrm{~b}$ & 100 & $\mathrm{a}$ & 100 & 100 \\
\hline & Green peach aphid & 0 & 0 & 0 & $\mathrm{c}$ & $46.9 \pm 7.3$ & $\mathrm{~b}$ & 100 & a & 100 & 100 \\
\hline & Tomato leaf miner fly & 0 & 0 & 0 & $\mathrm{c}$ & $15.9 \pm 6.8$ & $\mathrm{c}$ & 100 & a & 100 & 100 \\
\hline \multirow[t]{4}{*}{3} & Whitefly & 0 & 0 & 0 & $\mathrm{c}$ & 100 & a & 100 & a & 100 & 100 \\
\hline & Western flower thrips & 0 & 0 & 0 & $\mathrm{c}$ & $46.2 \pm 5.6$ & $\mathrm{~b}$ & 100 & $\mathrm{a}$ & 100 & 100 \\
\hline & Green peach aphid & 0 & 0 & 0 & $\mathrm{c}$ & $13.0 \pm 7.3$ & $\mathrm{c}$ & 100 & a & 100 & 100 \\
\hline & Tomato leaf miner fly & 0 & 0 & 0 & $\mathrm{c}$ & 0 & $\mathrm{~d}$ & $87.1 \pm 2.9$ & $\mathrm{~b}$ & 100 & 100 \\
\hline
\end{tabular}

Note. Seven to ten adult insects were used with each voltage and wind speed, and the means and standard deviations were calculated from five repetitions of the experiments. The letters on the means in each vertical column indicate significant differences (i.e., $p<0.05$ ) according to Tukey's method.

Higher voltages were required to be applied to the ICWs to capture insects with larger body sizes, and higher voltages were required at higher wind speeds. The force of the ICWs became stronger with increasing voltage applied to the ICWs. There were no significant differences in the capture rates for the three insect species (i.e., whiteflies, Western flower thrips, and green peach aphids) with similar body sizes for all wind speeds and 
voltages. For voltages in excess of $1.2 \mathrm{kV}$, the ICWs captured all of the insects for all wind speeds investigated. Video data demonstrate the attraction of the test insects to the ICWs (see Video Supplement 1 at http://www.ccsenet.org/journal/index.php/jas/article/view/56745/31036), and the electrostatic forces were sufficient to capture the insects at wind speeds of up to $7 \mathrm{~m} \mathrm{~s}^{-1}$. These results demonstrate that the 3L-DD screen at $1.2 \mathrm{kV}$ could eliminate with all major pest insects investigated under real-world conditions in the greenhouse. At lower voltages, however, the electrostatic forces were not sufficiently strong to capture the insects, and the whiteflies fluttered their legs, twisted their bodies, and then flew away from the ICW (see Video Supplement 2 at http://www.ccsenet.org/journal/index.php/jas/article/view/56745/31042); otherwise, they were blown away from the ICW by the blower. Based on these observations, in the subsequent experiments, a voltage of $1.2 \mathrm{kV}$ was applied to ensure successful capture of the insects at wind speeds of up to $3 \mathrm{~m} \mathrm{~s}^{-1}$.

In the second experiment, we monitored the invasion of pests into the greenhouse and their subsequent multiplication. In this assay, we detected two species of pest; i.e., whiteflies and tomato leaf miner flies. No other pests were detected during the experimental period. The major population of pests was whiteflies, and the number trapped on the Y-plates increased continuously during the experimental period; surveys were carried out every three weeks during the three-month period, and the average number of whiteflies on each Y-plate was found to be $47.5 \pm 18.9$ ( 3 weeks), $121.6 \pm 41.7$ ( 6 weeks), $1725.3 \pm 174.6$ ( 9 weeks) and $4662.9 \pm 548.3$ (12 weeks). The population of the tomato leaf miner flies was comparatively lower (see Figure $3 \mathrm{a}$ ); the average number of miner flies on each Y-plate was $3.0 \pm 1.2$ ( 3 weeks), $7.5 \pm 2.7$ ( 6 weeks), $8.0 \pm 4.3$ ( 9 weeks) and 13.2 \pm 5.6 (12 weeks).

The PCR-based detection assay showed that all of the trapped whiteflies were biotype-Q, and the fraction of biotype-Q whiteflies carrying TYLCV increased monotonically during the 3-month experimental period; we found that $31.6 \%$ carried the disease at 3 weeks, $62.3 \%$ at 6 weeks, $92.8 \%$ at 9 weeks and $98.4 \%$ at 12 weeks. The appearance of typical symptoms of TYLCV in the greenhouse tomatoes provided further evidence of the presence of the virus, as shown in Figure 3b. Symptoms of TYLCV were detected in 200 tomato plants in the greenhouse within the three-month period. 

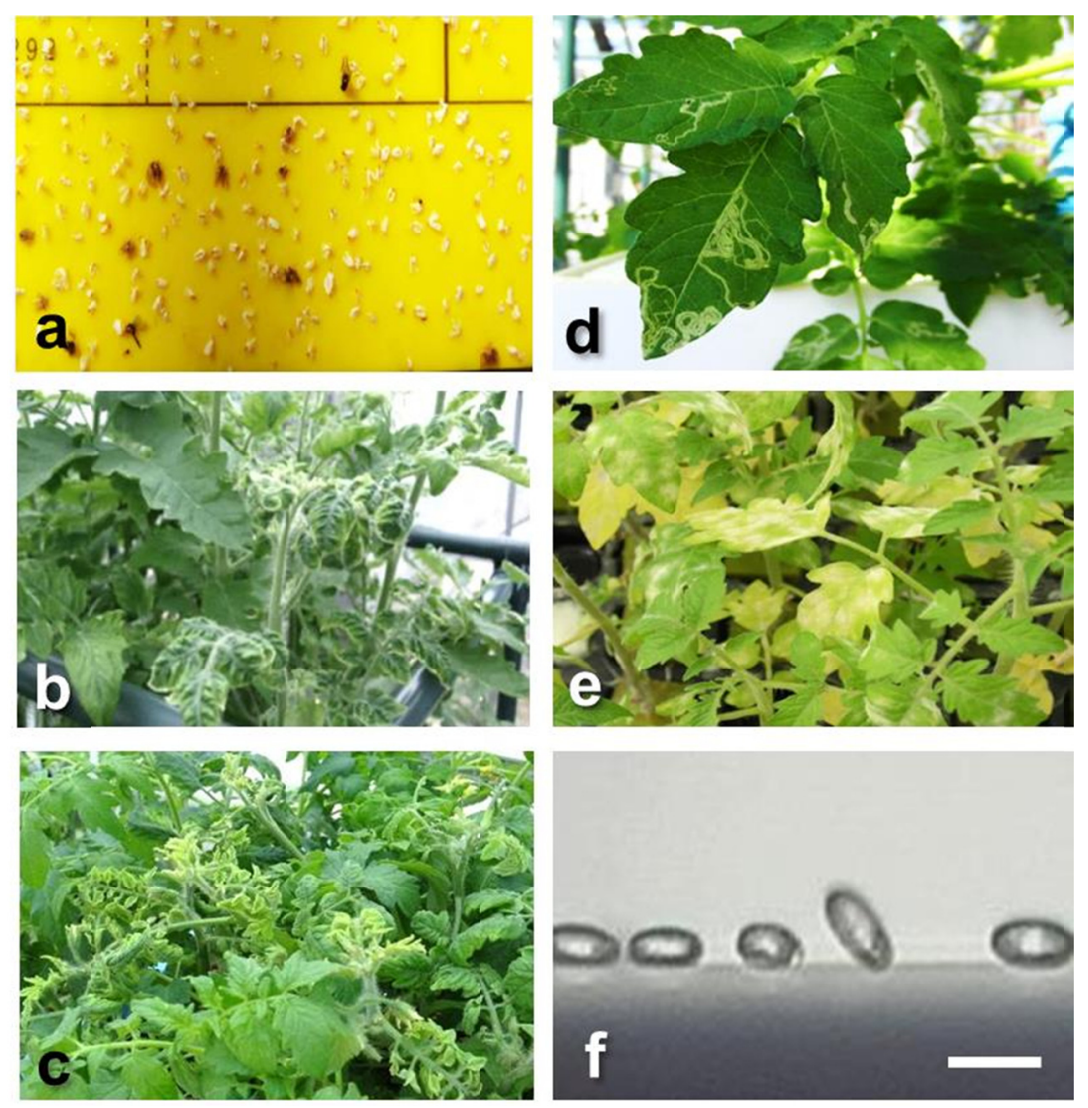

Figure 3. Photographs showing the captured pests and conidia, as well as the symptoms of disease and evidence of pest damage. (a) Whiteflies (small, white insects) and tomato leaf miner flies (larger, black insects) captured on a Y-plate. (b) Yellowing and curling symptoms of TYLCV on leaves of tomato plants in a propagation greenhouse. (c) TYLCV symptoms on the upper leaves of young tomato seedlings in non-electrified nursery shelter. (d) White trails on tomato leaves produced by larvae of the tomato leaf miner fly. (e) Colonies of tomato powdery mildew on leaves of young tomato seedlings in the non-electrified shelter. (f) Tomato powdery mildew conidia captured by an ICW photographed using a high-fidelity digital microscope.

The scale bar represents $20 \mu \mathrm{m}$

This heavy infestation of the greenhouse tomatoes by whiteflies was convenient to evaluate the efficacy of the electrostatic nursery shelter, as numerous whiteflies were incident on the shelters in the greenhouse. The movement of whiteflies from hydroponic tomato plants to the shelters was demonstrated in the control experiments, whereby the 3L-DD screens were not electrified. Numerous whiteflies were collected from tomato seedlings in the non-electrified shelter in three independent experiments (see Table 2). Symptoms of yellow leaf curl in the upper young leaves were detected on some tomato seedlings in the non-electrified shelter, as shown in Figure 3c. Clearly, the large population of the whiteflies on the tomato plants presented a significant risk to the tomato seedlings in the shelters in the greenhouse. 
Table 2. Evaluation of an electrostatic nursery shelter in terms of the ability to capture pests and conidia of tomato powdery mildew under greenhouse conditions

\begin{tabular}{|c|c|c|c|c|c|c|c|}
\hline \multirow{3}{*}{ Experiments } & \multirow{3}{*}{$\begin{array}{l}\text { 3L-DD screens } \\
\text { of shelter }\end{array}$} & \multicolumn{4}{|c|}{ Pest capturing assay } & \multirow{2}{*}{\multicolumn{2}{|c|}{$\begin{array}{c}\text { Spore capturing assay }^{\mathrm{a}} \\
\text { No. of tomato plants }\end{array}$}} \\
\hline & & \multicolumn{2}{|c|}{ No. of Whiteflies } & \multicolumn{2}{|c|}{ No. of Tomato leaf miner flies } & & \\
\hline & & $\begin{array}{l}\text { Trapped by } \\
\text { ICWs }\end{array}$ & $\begin{array}{l}\text { Colonizing } \\
\text { on plants }\end{array}$ & $\begin{array}{l}\text { Trapped by } \\
\text { ICWs }\end{array}$ & $\begin{array}{l}\text { Colonizing on } \\
\text { plants }\end{array}$ & Infected & Non-infected \\
\hline \multirow[t]{2}{*}{1} & Non-charged & 0 & 322 & 0 & 6 & 18 & 2 \\
\hline & Screen-charged & 431 & 0 & 4 & 0 & 0 & 20 \\
\hline \multirow[t]{2}{*}{2} & Non-charged & 0 & 613 & 0 & 16 & 17 & 3 \\
\hline & Screen-charged & 876 & 0 & 17 & 0 & 0 & 20 \\
\hline \multirow[t]{2}{*}{3} & Non-charged & 0 & 1217 & 0 & 24 & 19 & 1 \\
\hline & Screen-charged & 1478 & 0 & 21 & 0 & 0 & 20 \\
\hline \multirow[t]{2}{*}{4} & Non-charged & 0 & 1565 & 0 & 29 & 20 & 0 \\
\hline & Screen-charged & 3451 & 0 & 36 & 0 & 0 & 20 \\
\hline
\end{tabular}

Note. ${ }^{\text {a }}$ Spore capturing assay was conducted in a different greenhouse.

In addition to viral disease, silvery white mines on tomato leaves produced by the leaf miner larvae were also observed (Figure 3d), which allowed us to trace the entry of the tomato leaf miner flies into the shelter. The number of the leaf miner flies collected from the seedlings in the non-electrified shelter was small (Table 2), however, it can be attributed to their relatively low population in the greenhouse.

It is important to mention here that no pest was detected on the plants inside the electrified shelter. The tomato seedlings in this shelter remained free from pests during the entire three-month period in all experiments. These results clearly indicate that the $3 \mathrm{~L}-\mathrm{DD}$ screen was effective in excluding the pests from the shelter.

In the last experiment, we evaluated the applicability of the 3L-DD screen to control powdery mildew. Since there was no natural occurrence of powdery mildew on experimental greenhouse tomato plants, therefore, pathogen conidia were blown mechanically towards test seedlings from inoculated plants. On seedlings in the non-electrified (control) shelter, fungal colonies first appeared on a few leaves 3-4 days after exposure, and then spread to the other leaves of the plant and/or to the leaves of neighboring plants. Almost all the leaves of unguarded seedlings were infested with the pathogen by the end of the three-week test period (Figure 3e, Table 2). On the other hand, seedlings in the electrified shelter remained uninfected throughout the three-week test period Microscopic observation of the leaves showed that the plants in the electrified screen-guarded seedlings were free of conidia, and microscopic observation of the ICWs revealed that numerous conidia had been deposited on the surfaces of the ICWs (Figure 3f). These results showed that the 3L-DD screen was successful in preventing entry of the conidia into the shelter.

\section{Discussion}

The development of environmentally benign methods of protecting plants from pathogens and pests is desirable to replace conventional agrochemical methods, such as fungicides and insecticides. We investigated the use of electrostatic forces as an environmentally benign method of pest control. This approach has been used to prevent infection from the airborne conidia of powdery mildew (Moriura et al., 2006a, 2006b; Nonomura et al., 2009) and has been developed into a trap for aerial pathogens in glasshouses (Matsuda et al., 2006; Shimizu et al., 2007). The first electrostatic device that we reported was a screen that created a non-uniform electric field around insulated copper conducting wires arranged in parallel (Matsuda et al., 2006). The electric field generated an electrostatic force that could be used to attract fungal conidia entering the electric field. However, the screen required high voltages (i.e., $10-30 \mathrm{kV}$ ) to create sufficient force to attract airborne conidia. Recently, we reported that the use of two insulated electrodes with opposite polarity and with equal voltage to produce a large electrostatic force at lower voltages (i.e., 5.0-5.8 kV) (Matsuda et al., 2012). Nevertheless, such high voltages still present a risk of arc discharge from the screen (i.e., sparks), which may lead to fire or electric-shock accidents. To avoid these problems, it is essential to reduce the voltage applied to the conductors. This problem has been addressed using duplicate electric field barriers with opposite electric fields (Takikawa et al., 2014). This screen was able to operate with a voltage of $0.9 \mathrm{kV}$, and prevented passage of airborne spores of $P$. digitatum through the screen. 
The structure of the 3L-DD screen is similar to that of the single-layer double-charged dipolar electric field (1L-DD) screen (Matsuda et al., 2012); however, the earthed metal nets of the original screen were eliminated. With both types of screen, the high voltages required were produced using a Cockcroft circuit (Wegner, 2002). With the 1L-DD screen, however, the ICWs were negatively charged using electricity drawn from ground, and the nets were positively charged by pushing free electrons from the net to ground (Matsuda et al., 2012). Here we used the voltages to transfer electricity of the $\mathrm{ICW}(+)$ to the $\mathrm{ICW}(-)$. The $\mathrm{ICW}(+)$ and the ICW(-) were oppositely charged, and an electric field was formed between them (Figure 1c). The significance of this modification is the removal of the earth lines from both voltage sources, which renders the apparatus transferable. This made it simple to locate the electrostatic nursery shelter in the desired regions of the greenhouse.

Low power consumption is important for practical applications. In the electrostatic nursery shelter, the voltage source is the only part that required a power supply. This unit consumed only $5 \mathrm{~W}$, which is equivalent to that of a small electric light bulb. This characteristic enabled the use of a photovoltaic power generation method to supply power to the voltage sources. Using this system, we continuously operated six 3L-DD screens attached to a nursery shelter for the three-month period. During this time, the power supply was stable and was not disturbed by changes in weather; therefore, the screens were able to continuously protect the plants from spores and pests.

The main focus of this work was to examine the ability of the 3L-DD screen to capture the major pests of greenhouse-grown tomatoes. We investigated the four insect: species whiteflies, Western flower thrips, winged green peach aphids and tomato leaf miner flies. The original 1L-DD screen included earthed metal nets on both sides of the ICW layers, and repelled the insects from the screen (Nonomura et al., 2012). With the screen described here, we eliminated the earthed metal nets to trap insects that approached the screen. This mechanism of capturing insects has been described previously (Matsuda et al., 2012). Based on the insect-capture assay, we may draw the following conclusions. 1) The voltage of $1.2 \mathrm{kV}$ applied to the negative and positive ICWs of the $3 \mathrm{~L}-\mathrm{DD}$ screen provided sufficient electrostatic force to capture all of the insects that were blown towards the screen at speeds of up to $3 \mathrm{~m} \mathrm{~s}^{-1}$ (which is the maximum speed of winds inside the greenhouse); 2) the captured insects could not escape the ICW even when blown at $7 \mathrm{~m} \mathrm{~s}^{-1}$; and 3) the attractive force of the ICWs was not affected by replacing the earthed metal net in the original version. These results demonstrate the potential for practical applications as nursery shelters for the control of greenhouse pests.

One of the main aims of this work was to demonstrate protection against two species of greenhouse pests; i.e., whiteflies and tomato leaf miner flies, which are particularly problematic for greenhouse-grown tomatoes. These pests commonly infest greenhouses without proper control, and we prepared a heavily infested greenhouse, which enabled us to expose the seedlings in the electrostatic nursery shelter to repeated attack from these pests. Whiteflies have prevailed in our district (Nara prefecture) of Japan (Matsuda et al., 2013), and also over this study period, their visit was so incessant that the highly pest-infested situation could be made inside the greenhouse. In fact, the pest density at the time of assay was approximately 1000 -fold higher than ordinary levels (Matsuda et al., 2013), and this infestation was our desired level for evaluating the trapping ability of the shelter. We demonstrated that the pest-trapping performance by the electrified shelter was stable over a long period time under variable conditions in the greenhouse. This assay also provided an opportunity to examine the response of the shelter to larger pests under greenhouse conditions. The tomato leaf miner is one of the largest pests that permeate conventional woven insect nets (with a 1-2 mm mesh size) (Antibnus et al., 1998; Tinoco et al., 2014). In the non-electrified (control) shelter, we found that some seedlings were infested with both whiteflies and tomato leaf miner larvae; the upper leaves showed signs of whitefly infestation, and lower leaves of leaf miners (data not shown). These seedlings withered rapidly. These signs of infestation were not observed on the plants within the electrified shelter, which shows that it is a reliable method of protecting the plants from pests in the nursery environment.

The other main purpose of the work was to protect nursery-stage tomato seedlings from airborne pathogens. For seedlings at this stage, aerial infection by the fungal pathogens is a particularly significant problem. The final step of this work was to investigate the application of the electrostatic nursery shelter to protection from airborne conidia of tomato powdery mildew. We have previously discussed the electrostatic mechanism of capturing spores in the electric field generated by the 3L-DD screen (Takikawa et al., 2014). However, in that work there was little occurrence of powdery mildew disease during the three-month period of the experiments in the control plants. The method used here was artificial inoculation of seedlings with the pathogen inside the shelter by mechanically dissemination of abundant conidia produced on inoculum plants. The infection efficiency of this method was sufficiently high to produce fungal colonies on almost all of the leaves of the tomato seedlings in the non-electrified control shelter, which allowed us to demonstrate that our method was effective in controlling infection from airborne pathogens. The electrified shelter prevented the tomato plants from being exposed to the 
inoculum. This demonstrates that it is an effective alternative to the use of chemical fungicides during the nursery stage. This physical protection method is expected to be more attractive to the public than fungicides for high-value crops. We are currently in the process of developing this electrostatic nursery shelter as a commercial product for practical applications.

\section{Acknowledgements}

This work was supported in part by JSPS KAKENHI Grant Number 25450375 from the Ministry of Education, Culture, Sports, Science and Technology, Japan.

\section{References}

Antibnus, Y., Lapidot, M., Hadar, D., Messika, Y., \& Cohen, S. (1998). Ultraviolet-absorbing screens serve as optical barriers to protect crops from virus and insect pests. Journal of Economic Entomology, 91, 1401-1405. http://dx.doi.org/10.1093/jee/91.6.1401

Cohen, S., \& Berlinger, M. J. (1986). Transmission and cultural control of whitefly borne viruses. Agriculture, Ecosystems and Environment, 17, 89-97. http://dx.doi.org/10.1016/0167-8809(86)90030-7

Fukuta, S., Kato, S., Yoshida, K., Mizukami, Y., Ishida, A., Ueda, J., ... Ishimoto, Y. (2003). Detection of tomato yellow leaf curl virus by loop-mediated isothermal amplification reaction. Journal of Virological Methods, 112, 35-40. http://dx.doi.org/10.1016/S0166-0934(03)00187-3

Giacomelli, G. A., Ting, K. C., \& Mears, D. R. (1994). Design of a single truss tomato production system (STTPS). Acta Horticulturae, 361, 77-84. http://dx.doi.org/10.17660/ActaHortic.1994.361.6

Horowitz, A. R., Kontsedalov, S., \& Ishaaya, I. (2004). Dynamics of resistance to the neonicotinoids acetamiprid and thiamethoxam in Bemisia tabacci (Homoptera: Aleyrodidae). Journal of Economic Entomology, 97, 2051-2056. http://dx.doi.org/10.1093/jee/97.6.2051

Hsieh, C. H., Wang, H. Y., Chen, Y. F., \& Ko, C. C. (2012). Loop-mediated isothermal amplification for rapid identification of biotypes B and Q of the globally invasive pest Bemisia tabaci, and studying population dynamics. Pest Management Science, 68, 1206-1213. http://dx.doi.org/10.1002/ps.3298

Kashimoto, K., Sameshima, T., Matsuda, Y., Nonomura, T., Oichi, W., Kakutani, K., Nakata, K., ... Toyoda, H. (2003b). Infectivity of a Japanese isolate of Oidium neolycopersici KTP-01 to a European tomato cultivar resistant to $O$. lycopersici. Journal of General Plant Pathology, 69, 406-408. http://dx.doi.org/10.1007/s10327-003-0070-y

Matsuda, Y., Ikeda, H., Moriura, N., Tanaka, N., Shimizu, K., Oichi, W., Nonomura, T., ... Toyoda, H. (2006). A new spore precipitator with polarized dielectric insulators for physical control of tomato powdery mildew. Phytopathology, 96, 967-974. http://dx.doi.org/10.1094/PHYTO-96-0967

Matsuda, Y., Kakutani, K., Nonomura, T., Kimbara, J., Kusakari, S., Osamura, K., \& Toyoda, H. (2012). An oppositely charged insect exclusion screen with gap-free multiple electric fields. Journal of Applied Physics, 112, 116103(-1)-116103(-3). http://dx.doi.org/10.1063/1.4767635

Matsuda, Y., Kashimoto, K., Takikawa, Y., Aikami, R., Nonomura, T., \& Toyoda, H. (2001). Occurrence of new powdery mildew on greenhouse tomato cultivars. Journal of General Plant Pathology, 67, 294-298. http://dx.doi.org/10.1007/PL00013034

Matsuda, Y., Mori, Y., Nishida, M., Sakano, S., Tarumoto, K., Nonomura, T., ... Toyoda, H. (2005a). Screening of wild Lycopersicon species for resistance to Japanese isolate of tomato powdery mildew Oidium neolycopersici. Breeding Science, 55, 355-360. http://doi.org/10.1270/jsbbs.55.355

Matsuda, Y., Sameshima, T., Moriura, N., Inoue, K., Nonomura, T., Kakutani, K., ... Toyoda, H. (2005b). Identification of individual powdery mildew fungi infecting leaves and direct detection of gene expression by single conidium PCR. Phytopathology, 95, 1137-1143. http://dx.doi.org/10.1094/PHYTO-95-1137

Matsuda, Y., Setomoto, M., Yoshimoto, N., Nonomura, T., Kakutani, K., Takikawa, Y., \& Toyoda, H. (2013). Identification of Bemisia tabaci biotypes and detection of TYLCV from diseased tomato plants and viruliferous biotype $\mathrm{Q}$ whiteflies. Memoirs of the Faculty of Agriculture of Kinki University, 46, 1-5.

Mori, Y., Matsuda, Y., Nonomura, T., Nishimura, H., Kusakari, S., \& Toyoda, H. (2004). Sensitivity of tomato powdery mildew Oidium neolycopersici to commercially available fungicides. Japanese Journal of Phytopathology, 70, 233-234.

Moriura, N., Matsuda, Y., Oichi, W., Nakashima, S., Hirai, T., Nonomura, T., ... Toyoda, H. (2006b). An 
apparatus for collecting total conidia of Blumeria graminis f. sp. hordei from leaf colonies using electrostatic attraction. Plant Pathology, 55, 367-374. http://dx.doi.org/10.1111/j.1365-3059.2006.01356.x

Moriura, N., Matsuda, Y., Oichi, W., Nakashima, S., Hirai, T., Sameshima, T., ... Toyoda, H. (2006a). Consecutive monitoring of lifelong production of conidia by individual conidiophores of Blumeria graminis f. sp. hordei on barley leaves by digital microscopic techniques with electrostatic micromanipulation. Mycological Research, 110, 18-27. http://dx.doi.org/10.1016/j.mycres.2005.09.007

Murai, T. (1991). Rearing method for clones of some aphids on tick bean, Vicia faba. Bulletin of the Shimane Agricultural Experiment Station, 25, 78-82.

Murai, T., \& Loomans, A. J. M. (2001). Evaluation of an improved method for mass-rearing of thrips and a thrips parasitoid. Entomologia Experimentalis et Applicata, 101, 281-289. http://dx.doi.org/10.1046/j.1570-7458.2001.00913.x

Nauen, R., \& Denholm, I. (2005). Resistance of insect pests to neonicotinoid insecticides: Current status and future prospects. Advances of Insects Biochemistry and Physiology, 58, 200-215 http://dx.doi.org/10.1002/arch.20043

Nonomura, T., Matsuda, Y., Kakutani, K., Kimbara, J., Osamura, K., Kusakari, S., \& Toyoda, H. (2012). An electric field strongly deters whiteflies from entering window-open greenhouses in an electrostatic insect exclusion strategy. European Journal of Plant Pathology, 134, 661-670. http://dx.doi.org/10.1007/s10658-012-0014-5

Nonomura, T., Matsuda, Y., Kakutani, K., Takikawa, Y., \& Toyoda, H. (2008). Physical control of powdery mildew (Oidium neolycopersici) on tomato leaves by exposure to corona discharge. Canadian Journal of Plant Pathology, 30, 517-524. http://dx.doi.org/10.1080/07060660809507551

Nonomura, T., Matsuda, Y., Xu, L., Kakutani, K., Takikawa, Y., \& Toyoda, H. (2009). Collection of highly germinative pseudochain conidia of Oidium neolycopersici from conidiophores by electrostatic attraction. Mycological Research, 113, 364-372. http://dx.doi.org/10.1016/j.mycres.2008.11.012

Oliveira, M. R. V., Henneberry, T. J., \& Anderson, P. (2001). History, current status, and collaborative research projects of Bemisia tabaci. Crop Protection, 20, 709-723. http://dx.doi.org/10.1016/S0261-2194(01)00108-9

Palumbo, J. C., Horowitz, A. R., \& Prabhaker, N. (2001). Insecticidal control and resistance management for Bemisia tabaci. Crop Protection, 20, 739-765. http://dx.doi.org/10.1016/S0261-2194(01)00117-X

Prabhaker, N., Coudriet, D. L., \& Meyerdirk, D. E. (1985). Insecticide resistance in the sweetpotato whitefly, Bemisia tabaci (Homoptera: Aleyrodiae). Journal of Economic Entomology, 78, 748-752. http://dx.doi.org/10.1093/jee/78.4.748

Sharaf, N. (1986). Chemical control of Bemisia tabaci. Agriculture, Ecosystems and Environment, 17, $111-127$. http://dx.doi.org/10.1016/0167-8809(86)90032-0

Shimizu, K., Matsuda, Y., Nonomura, T., Ikeda, H., Tamura, N., Kusakari, S., ... Toyoda, H. (2007). Dual protection of hydroponic tomatoes from rhizosphere pathogens Ralstonia solanacearum and Fusarium oxysporum f. sp. radicis-lycopersici and airborne conidia of Oidium neolycopersici with an ozone-generative electrostatic spore precipitator. Plant Physiology, 56, 987-997. http://dx.doi.org/10.1111/j.1365-3059.2007.01681.x

Takikawa, Y., Matsuda, Y., Kakutani, K., Nonomura, T., Okada, K., Kusakari, S., \& Toyoda, H. (2015). Electrostatic insect sweeper for eliminating whiteflies colonizing host plants: A complementary pest control device in an electric field screen-guarded greenhouse. Insects, 6, $442-454$. http://dx.doi.org/10.3390/insects6020442

Takikawa, Y., Matsuda, Y., Nonomura, T., Kakutani, K., Kimbara, J., Osamura, K., ... Toyoda, H. (2014). Electrostatic guarding of bookshelves for mould-free preservation of valuable library books. Aerobiologia, 30, 435-444. http://dx.doi.org/10.1007/s10453-014-9340-8

Tanaka, N., Matsuda, Y., Kato, E., Kokabe, K., Furukawa, T., Nonomura, T., ... Toyoda, H. (2008). An electric dipolar screen with oppositely polarized insulators for excluding whiteflies from greenhouses. Crop Protection, 27, 215-221. http://dx.doi.org/10.1016/j.cropro.2007.05.009 
Tinoco, C. E., Gutiérrez, G. A. M., Bolaños, T. A., \& Sánchey, D. M. (2014). Screen porosity and exclusion of pests in greenhouse tomatoes (Solanum lycopersicum L.). Southwestern Entomologist, 39, 625-634. http://dx.doi.org/10.3958/059.039.0321

Ueda, S., \& Brow, J. K. (2006). First report of the Q biotype of Bemisia tabaci in Japan by mitochondrial cytochrome oxidase I sequence analysis. Phytoparasitica, 34, 405-411. http://dx.doi.org/10.1007/BF02981027

Wegner, H. E. (2002). Electrical charging generators. In E. Geller et al. (Eds.), McGraw-Hill Encyclopedia of Science and Technology (9th ed., pp. 42-43). New York: The Lakeside Press.

Weintraub, P. G., \& Berlinger, M. J. (2004). Physical control in greenhouses and field crops. In A. R. Horowitz \& I. Ishaaya (Eds.), Insect Pest Management (pp. 301-318). Springer-Verlag, Berlin. http://dx.doi.org/10.1007/978-3-662-07913-3_12

\section{Copyrights}

Copyright for this article is retained by the author(s), with first publication rights granted to the journal.

This is an open-access article distributed under the terms and conditions of the Creative Commons Attribution license (http://creativecommons.org/licenses/by/3.0/). 